\title{
OOA composite structures applicable in railway industry
}

\author{
Soňa Rusnáková ${ }^{*}$, Milan Žaludek ${ }^{1}$, Milena Kubišová ${ }^{1}$, and Vladimír Rusnák ${ }^{2}$ \\ ${ }^{1}$ Tomas Bata University in Zlín, Department of Production Engineering, Vavrečkova 275, \\ 76001 Zlín, Czech Republic \\ ${ }^{2}$ VŠB - Technical University of Ostrava, Faculty of Metallurgy and Materials Engineering, \\ Department of Material Engineering, 17.listopadu 15, 70833 Ostrava - Poruba
}

\begin{abstract}
Composite sandwich structures offers several advantages over conventional structural materials such as lightweight, high bending and torsional stiffness, superior thermal insulation and excellent acoustic damping. In the aerospace industry, sandwich composites are commonly manufactured using the autoclave process which is associated with high operating cost. Out-of-autoclave (OOA) manufacturing has been shown to be capable of producing low cost and high performance composites. In this paper we present results of experimental testing of various sandwich materials according various standards and actual requirements in transport industry. We compared the different types of surface and paint systems, because these layers are the most important in contact with the surrounding environment and load conditions. In the experimental measurements were used various materials. For the core of the sandwich structure were selected aluminium honeycomb, aramid honeycomb and PET (Polyethylene terephthalate) foam core. Support layers were chosen two kinds of predimpregnated materials. The conditions of measurements were requirements for strength and rigidity, safety - flame resistance and reflectivity resistance. The samples were tested at the 3 - point bending test according to standard EN ISO 178, by modified test to determine the force required to rapture threaded insert, by test of reflectivity according to UIC CODE 844-4 $\mathrm{R}$ and according to standard EN 45545-2 fire protection of railway vehicles.
\end{abstract}

\section{Out-of autoclave technology}

The majority of high performance composite structures are manufactured in autoclaves. Autoclave processing of composites uses primarily pre-impregnated unidirectional fibers or fabrics (prepregs) that are cured at $180^{\circ} \mathrm{C}$ and consolidated with $6 \mathrm{~atm}$ of pressure, usually. A large database of design allowable for autoclave prepregs is available and accessible to product designers. This well-established process requires high infrastructure investment for

\footnotetext{
* Corresponding author: rusnakova@,ft.utb.cz
} 
autoclaves as well as high recurring tooling costs. The maximum component size is limited by the size of available autoclaves. Alternative processing methods need to be investigated in order to reduce production costs and broaden the supply base of composite structures. This presentation addresses the application of a relatively new class of composite materials using out-of-autoclave (OOA) technologies. The advantages of OOA processes include substantially lower infrastructure, tooling, and overall manufacturing costs. [1-2]

For OOA technologies using predimpregated materials (pre-preg) belong to curing of prepregs in oven and PCM (Prepreg Compression Moulding).

\section{Fire resistance}

In case of fire, the composite is protected by foam formation, which is isolated from oxygen. To be absolutely halogen-free, smoke toxicity and opacity is dramatically reduced. Fire resistance in the railway industry defines standard EN 45545-2 Fire protection of railway vehicles. The standard specifies reaction to fire-intensive materials and products used in rail vehicles. It is based on existing fire safety regulations for rail vehicles in the International Union of Railways and various European countries. Each state has its own testing methods that are adapted to local conditions and customs. Individual test methods cannot be compared together, slow down the adjustment process. [3-4]

For each product is determined by the specific requirements set by standards - R:

- Interior (panels, baggage, window frames, flat bar),

- Exterior (seat cushions, covers, air section),

- $\quad$ Furniture (seat cushions, covers, mattresses, bedding),

- $\quad$ Electronic equipment (cables, housings, insulation material, resistors),

- Mechanic equipment (flexible steel / rubber parts).

The test materials are classified according to this standard (EN 45545) into the category R1, which is valid for the entire European Union since 2013 and unites the most important requirements for non-flammability, toxicity and emissions of flue gas and heat. [5] For this category of material are required to test these basic tests:

Determining Hazard Level (HL)

Fire resistance levels (HL1,2,3) is measured using the following five tests:

- $\quad$ CFE $\left(\mathrm{kW} / \mathrm{m}^{2}\right)$ : Critical Flux at extinction or lateral spread of flame

- $\quad$ MAHRE $\left(\mathrm{kW} / \mathrm{m}^{2}\right)$ : The maximum rate of heat release

- Ds (4): Specific optical density of smoke

- VOF4: Cumulative value of specific optical densities in the first 4 minutes of the test

- $\quad$ CITG 8min Conventional Toxicity Index (C02, CO, HF, HCl, HBr, HCN, NOx, SO2)

Table 1. Construction categories [6]

\begin{tabular}{|l|l|l|l|l|}
\hline Operation Category & $\begin{array}{l}\mathbf{N} \\
\text { Standard vehicles }\end{array}$ & $\begin{array}{l}\text { A } \\
\text { Automatic train } \\
\text { without trained } \\
\text { personal }\end{array}$ & $\begin{array}{l}\mathbf{D} \\
\text { Double decked } \\
\text { vehicles }\end{array}$ & $\begin{array}{l}\text { S } \\
\text { Sleeping and } \\
\text { couchette vehicles }\end{array}$ \\
\hline \hline $\begin{array}{l}\mathbf{1} \\
\text { On infrastructure }\end{array}$ & HL1 & HL1 & HL1 & HL2 \\
\hline $\begin{array}{l}\mathbf{2} \text { Underground Tunel } \\
<\mathbf{5 k m} \\
\text { With side evacuation }\end{array}$ & HL2 & & HL2 & \\
\hline $\begin{array}{l}\mathbf{3} \\
\text { Underground Tunel } \\
>\mathbf{5 k m}\end{array}$ & & HL2 & HL2 \\
\hline $\begin{array}{l}\mathbf{4} \\
\text { Underground } \\
\text { Without side evacuation }\end{array}$ & HL3 & HL2 & HL2 & HL3 \\
\hline
\end{tabular}




\section{Experimental part}

\subsection{Tested samples}

The samples were made in the form of flat plates by hand-laying pre-preg technology and subsequent curing in the oven. The technology is more suitable for piece production. Used materials for the production of sandwich panels:

- Pre-preg 1 - Fiber-reinforced, thermosetting pre-impregnated material with excellent FST and mechanical properties. It is halogen free modified phenolic system with $42 \%$ phenolic resin. Fabric of E-glass Yarn, 300g/m2, $8 \mathrm{H}$ satin weave.

- Pre-preg 2 - Fibrous-reinforced thermosetting pre-impregnated material with excellent FST and mechanical properties. It is a halogen-free phenolic system with $47 \%$ phenolic resins. Fabric of E-glass Yarn, $300 \mathrm{~g} / \mathrm{m} 2$, $8 \mathrm{H}$ satin weave. It is highly adhesive to aluminium.

- Foam - Closed thermoplastic pores and recyclable polymer foam with excellent smoke, toxic and fire properties. It is the ideal sandwich core material applied where high fire resistance is required.

- Aramid honeycomb - It is the main component of sandwich in industrial sectors with high dimensional stability in heat and humidity. The honeycomb used per square meter has a density of 32 cells, a cell size of $4.8 \mathrm{~mm}$, a compressive strength of $0.9 \mathrm{MPa}$, a shear strength of $0.55 \mathrm{MPa}$, a shear modulus of $18 \mathrm{MPa}$.

- Aluminium honeycomb - core of aluminium honeycomb. The honeycomb used has a density of $77 \mathrm{~kg} / \mathrm{m}^{3}$, a cell size of $4.8 \mathrm{~mm}$, a compressive strength of $3.94 \mathrm{~N} / \mathrm{mm}^{2}$, a shear strength of $2.29 \mathrm{~N} / \mathrm{mm}^{2}$.

\subsection{Description of samples}

Sample 2A

Consisting of Aramid honeycomb and 2 layers of prepreg on each side - referred to as $2 \mathrm{~A}$

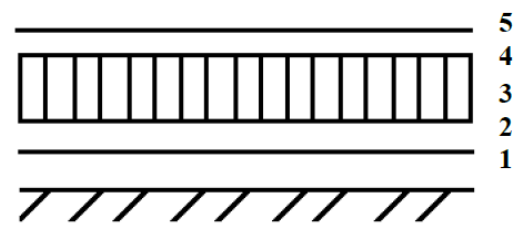

Fig.1. Composition of sample 2A - 1,2,4,5 pre-pregs 1; 3 Aramid honeycomb.

Sample 3A

Consisting of Aramid honeycomb and 3 layers of pre-preg on each side - referred to as $3 \mathrm{~A}$

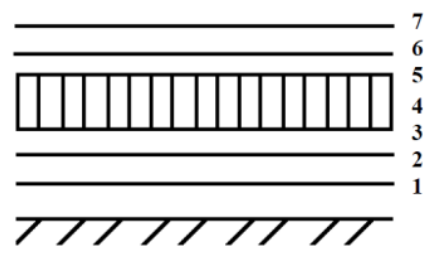

Fig.2. Composition of sample 3A - 1,2,3,5,6,7 pre-pregs 1; 4 Aramid honeycomb. 
Sample 4A

Consisting of Aramide honeycomb and 4 layers of pre-preg on each side referred to as $4 \mathrm{~A}$

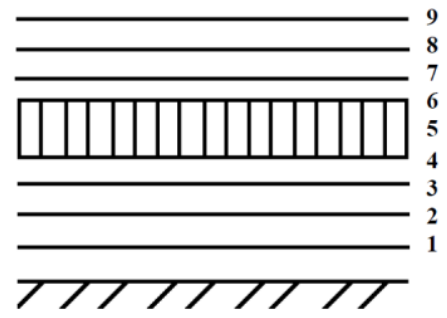

Fig. 3. Composition of sample 4A - 1,2,3,4,6,7,8,9 pre-pregs; 5 Aramid honeycomb.

The samples referred to as $2 \mathrm{~B}, 3 \mathrm{~B}$ and $4 \mathrm{~B}$ are the same composition like samples referred $2 \mathrm{~A}, 3 \mathrm{~A}$ and $4 \mathrm{~A}$, but instead of Aramid honeycomb is like a core material used polymer foam.

The samples referred to as $2 \mathrm{C}, 3 \mathrm{C}$ and $4 \mathrm{C}$ are the same composition like samples referred 2A, $3 \mathrm{~A}$ and $4 \mathrm{~A}$, but instead of Aramid honeycomb is like a core materials used aluminium honeycomb.

\section{Experimental testing of mechanical and FST properties}

\subsection{Three-point bending test 5}

The test was carried out on Zwick 1456 according to ČSN EN ISO 178. The test samples were tested at room temperature $23^{\circ} \mathrm{C}$. Sample sizes were determined at $100 \times 20 \mathrm{~mm}$.

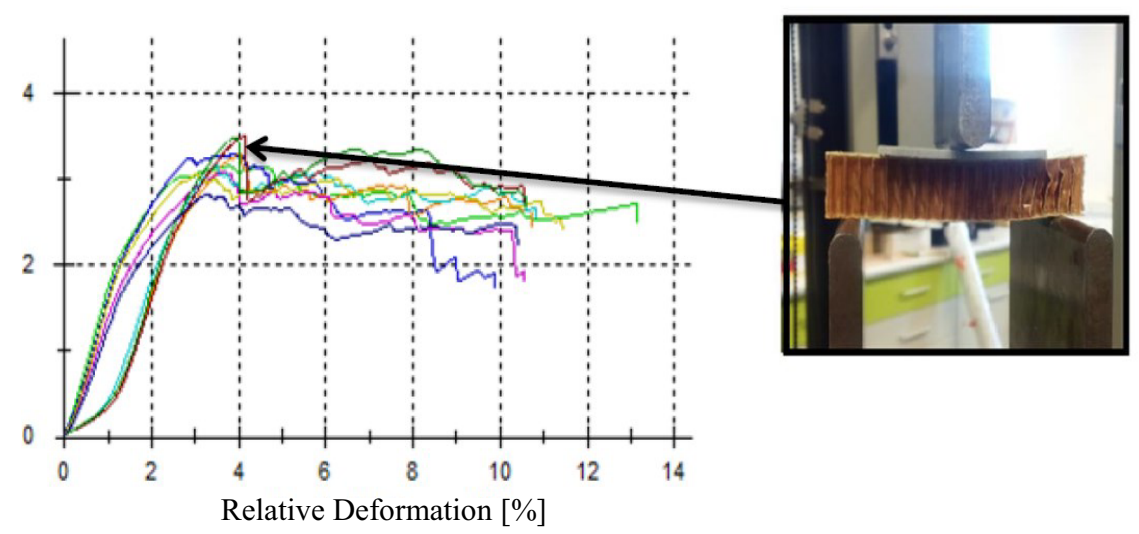

Fig. 4. Results for sample 2A, with view on arrangement during 3-point bending test. 


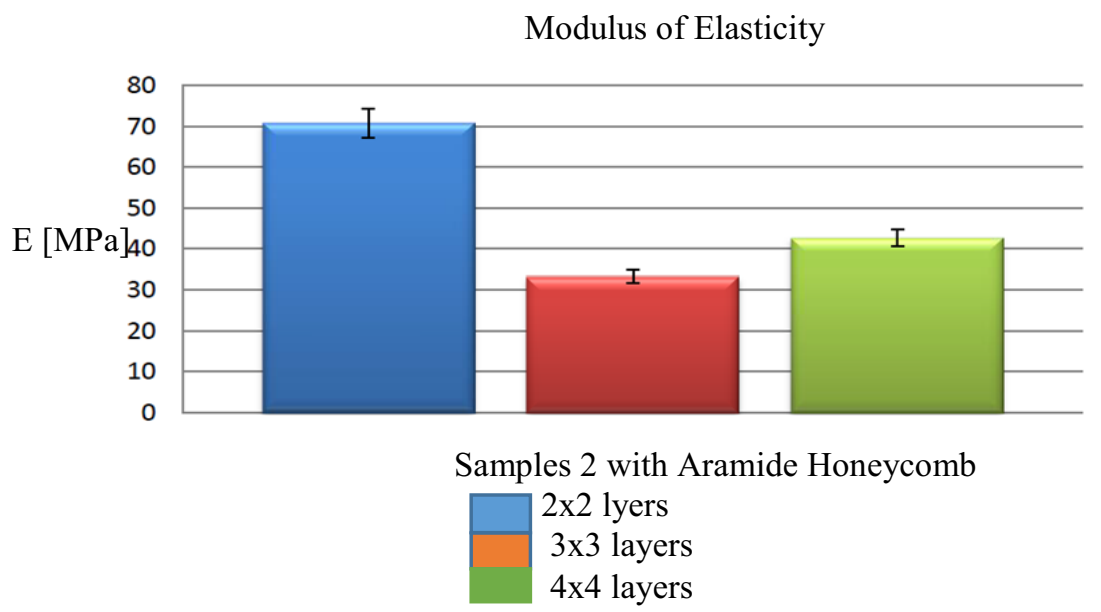

Fig. 5. Evaluation of Modulus of Elasticity in 3-point Bend Testing for Samples A.

The best fit in the bending test a Type $\mathrm{C}$ samples with an aluminium honeycomb core. The largest modulus of elasticity was measured $1860 \mathrm{MPa}$ for the $\mathrm{C}$ sample with $3 \times 3$ prepreg layers. On the contrary, the most severe modulus of elasticity resembled Type B samples with a foam core. Throughout the course of the test, the malfunctions were also recorded, which in most cases were of a generic nature and most often caused a violation of the cohesiveness between the core and the outer layer.

The highest value of the strength limit was 29.7 MPa for C type samples. Again, it turned out that the best type of core is the aluminum honeycomb, which shows the best results of the strength of all the samples tested. Worst results were obtained with the Aramid honeycomb sample A, which reached the minimum strength limits, the lowest strength was measured in a type A sample with $2 \times 2$ layers of pre-preg, namely $3.21 \mathrm{MPa}$. The most suitable materials are C-samples with aluminum honeycomb. In both cases, as with the strength limit or the modulus of elasticity, it comes out with the highest values.

\subsection{Cone calorimeter}

Samples of sandwich composite structures with two different painting systems. The size of the samples used for the conical calorimeter test were in accordance with the requirements of the technical standards ISO 5660-1 and ISO 5660-2. Samples were conditioned prior to the test according to ISO 5660-1.

\subsubsection{Painting systems}

Painting system 1 - consists of a filler and a top coat

1. Filler - It is a two-component, high-particle polyurethane based filling material. It has high chemical and mechanical resistance.

2. Top layer - This is a two-component polyurethane-based structural varnish with antigraffiti properties. It is possible to create single-layer smooth or scarred (Nar-ben) surfaces and two-layer pearl structural effects. Cured film is abrasion-resistant, scratch-free, repellent, and easy to clean.

Painting system 2 - contains filler and top coat.

1. Filler - is a two-component polyurethane spray anti-corrosion filler for the creation of a high quality substrate under the top layer. Depending on the degree of dilution, either thick layers can be created to fill rough surface roughness, or thin, highly rigid and even layers. 
2. Top layer - Two-component varnish based on polyurethane resin for semi-gloss. It is possible to create smooth thin layers. These treatments have high film strength, good chemical resistance and weather resistance.

Samples were tested at a heat flow density of $50 \mathrm{kWm}^{-2}$. The orientation of the samples during the test was horizontally.

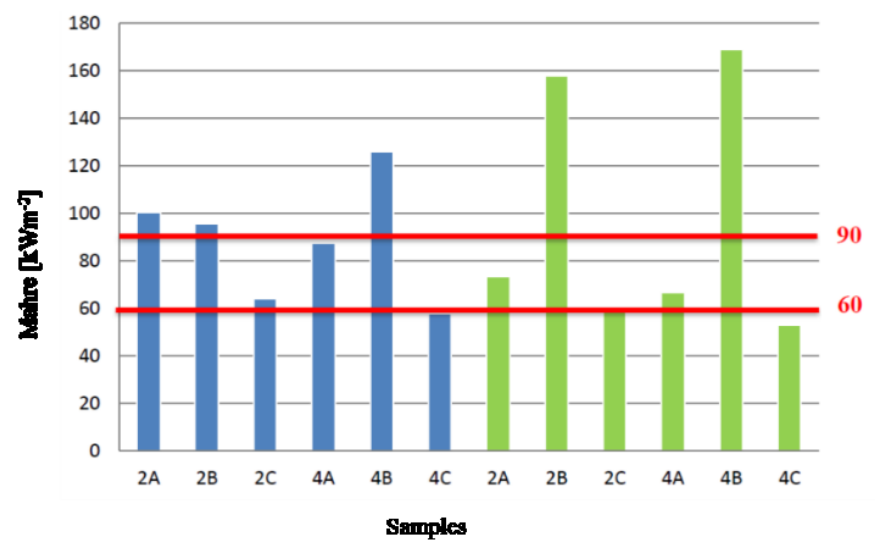

Painting System 1

Painting System 2

Fig. 6. Measured values with marked limits for the category HL2.

Conditions during the exam:

- Ambient temperature: 20 to $21^{\circ} \mathrm{C}$

- Relative humidity: 52 to $55 \%$

- $\quad$ Atmospheric pressure: 98.8 to $99.5 \mathrm{kPa}$

- Density of the heat flow reaching the surface of the tested samples: $50 \mathrm{kWm}^{-2}$

- Air flow through the hood: $0,024 \mathrm{~m}^{3} / \mathrm{s}$

The maximum average heat release rate is a basic feature that highlights the fire risk of the material. Initiation time and Maximum Average Rate of Heat Emission (Marhe).

All samples tested showed a maximum average heat release rate of less than $40 \mathrm{~kW} \mathrm{~m}^{-2}$ within $20 \mathrm{~s}$ of the test. During the entire test duration, the Marhe value was less than $90 \mathrm{~kW}$ $\mathrm{m}^{-2}$, only the samples $2 \mathrm{C}, 4 \mathrm{~A}, 4 \mathrm{C}$ for the coating system 1 , and for the samples were $2 \mathrm{~A}, 2 \mathrm{C}$, $4 \mathrm{~A}$ and $4 \mathrm{C}$. The data on the maximum average heat release rate, the time-dependent rate of heat release, the total amount of released heat, and the specific $\mathrm{CO}$ release rate depend on the atmospheric pressure at which they were determined, with the increasing altitude decreasing both the maximum and average heat release rates. The nature of the samples also results in the high sensitivity of the data obtained from the way they are stored in the holder. In the case of insufficient mineral wool support in the holder, the tilt can occur during the test and subsequent very rapid burning of the filling part of the samples examined. Significant impact on the data obtained also has the side of the sample from which it is subjected to thermal radiation during the test. It is possible to see how the individual test results differ significantly, due to the different material composition and non-homogeneity of the materials in the samples. All samples were tested according to EN 45545-2. It was mainly about finding out whether the tested materials met the HL2 category and had to move between $60-90\left[\mathrm{kWm}^{-2}\right]$. In order to be used in most design categories.

We evaluated two coating systems for samples $2 \mathrm{~A}, 2 \mathrm{~B}, 2 \mathrm{C}$ and $4 \mathrm{~A}, 4 \mathrm{~B}, 4 \mathrm{C}$. We focused on the maximum average heat release rate called Marhe $\left[\mathrm{kWm}^{-2}\right]$. Samples with paper 
honeycomb $2 \mathrm{~A}$ and $4 \mathrm{~A}$ at both coating systems reached values below 90 [kWm-2] up to sample 2A with a painting system 1 at $100\left[\mathrm{kWm}^{-2}\right]$ and therefore not meeting the HL2 category. Poor results were obtained with the foam core $2 \mathrm{~B}$ and $4 \mathrm{~B}$ in both paint systems, when the outer layers burnt rapidly, and the foam core was rapidly burnt. These samples have

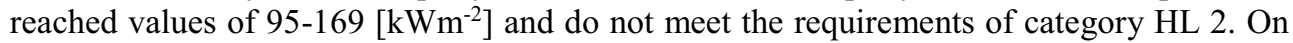
the other hand, the best results were obtained with samples of aluminum $2 \mathrm{C}$ and $4 \mathrm{C}$ of both paint systems. Samples 4C showed the best values of all 52 and $57\left[\mathrm{kWm}^{-2}\right]$ and thus even meet the higher HL3 category. Better results were obtained with the sample system 2, which had lower values than system 1 .

\section{Results}

Research paper serves as a basis for the development of a new structure of the sandwich structure, which could start to be applied in the railway industry produced by OOA technology.

Various types of surface and coating systems were compared. Different materials were used for experimental measurements. For the core of the sandwich structure, aluminium honeycombs, Aramid honeycombs, and a foam polymeric PET core were selected, and on the outer layers 2 types of pre-pregs.

Based on requirements for strength and stiffness, safety self-extinguishing, wear resistance, samples were tested for 3-point bending according to EN ISO 178 standard, modified test to determine the force required to pull the thread insert, UIC CODE $844-4 \mathrm{R}$ and according to the standard ČSN EN 45545 - 2 fire protection of railway vehicles, the cone calorimeter test according to ISO 5660-1 was selected.

In all tests, the samples with the foam core have the lowest values and have not met either standard requirement.

The solution is to use a different type of foam with better mechanical properties or to adjust the number of individual pre-preg layers that can be replaced by other types of prepregs. Sandwich structures with a foam core are very easily mouldable and can also produce very complex products. [7]

For samples with Aramid honeycomb, variable results were obtained for all tests. In the bending test, they reached the lowest values of all tested materials. Self-extinguishing samples matched, except for one that had only two layers of pre-preg. For wear resistance the best result was achieved by sample 4A, but it didn't meet the requirements of the standard. The next proposal is to change the honeycomb, to another with a higher cell density, thereby increasing strength and stiffness.

The highest and best values were obtained with aluminium honeycomb samples. In the bending test, they reached up to several times the strength and modulus of flexural strength compared to the paper and foam core samples. They achieved a conical calorimeter evaluation all samples of very good results and meet the HL2 category. Quadruple samples also met the HL3 category.

Appropriate combinations of materials that would already meet all requirements for the railway industry must be further developed and tested. The resulting product must have sufficient strength and stiffness, safety, functionality, wear resistance, but a very important condition is also the low weight.

This work and the project is realized with the financial support of the internal grant of TBU in Zlín No. IGA/FT/2017/002 funded from the resources of specific university research. 


\section{References}

1. NIU, M. C. Y. Composites Airframe Structures; Practical Design Information and Data. 1st ed. (Hong Kong: Conmilit Press Ltd., 664 s., 1992)

2. VINSON, J. R., The Behavior of Sandwich Structures of Isotropic and Composite Materials. 1st (Ed. New York: CRC Press, 378 s., 1999)

3. BITZER, T. N. Honeycomb Technology: Materials, Design, Manufacturing, Applications and Testing. 1st ed. (London: Chapman \& Hall, 233 s., 1997)

4. ZENKERT, D. Nordic Industrial Fund, The Handbook of Sandwich Construction (Worcestershire: EMAS Publishing, 447 s., 1997)

5. LEHMHUS D., BUSSE M., HERRMANN A., KAYVANTASH K. Structural Materials and Processes in Transportation, (1st ed. New York: Wiley-VCH Verlag GmbH, 598s., 2013)

6. DOSTAL C. A. Engineered Materials Handbook: Composites, Volume 1, (Ohio: ASM International, 983 s., 1987)

7. GUPTA K. M. Engineering Materials: Research, Applications and Advances, (1st ed. Boca Raton: CRC Press, 636 s., 2014) 